\title{
METHODOLOGY OF PROBLEM ANALYSIS IN THE QUALITY MANAGEMENT SYSTEM WITH THE USE OF SYSTEMS APPROACH
}

\author{
Mariusz J. LIGARSKI \\ Silesian University of Technology
}

\begin{abstract}
:
In the work there is an innovative methodology of problem analysis presented in the quality management system with the use of systems approach. The methodology serves for determination of action mechanism of unfavorable phenomena occurring in the systems and for explaining their causes. There are assumptions of the elaborated methodology described. For the first time there are the rules of systems thinking used for the analysis of unfavorable phenomena and the system archetypes were applied. Special attention is paid to appropriate presentation of the examined situation in a perspective of systems thinking as well as correct selection of systems archetype. There is a need emphasized concerning examining the situation with the inclusion of numerous variables and necessity to reach to the primary causes of the analyzed phenomena. The elaborated methodology was proceeded to validation on the basis of two threats described by different systems archetypes. There are schemes presented which feature the action mechanism of unfavorable phenomena. The confirmation of methodology in practice proved its application possibilities. Finally, the elaborated methodology was subject to analysis. The discussion of its possibilities and limitation was also conducted.
\end{abstract}

Key words: methodology, problem analysis, quality management system, systems approach, systems thinking

\section{INTRODUCTION}

Systems approach has been undergoing its renaissance in the management sciences since 90s of 20th century. Many textbook publications on systems approach [1, 2, 3, $13,15]$, have appeared in which authors pay attention to application possibilities of this approach. A book by Peter $M$. Senge "The Fifth Discipline", published for the first time in 1990 and treating about systems thinking in management, has become a bestseller and made a breakthrough in the approach to organization management. Peter M. Senge proposed a conception of systems approach which says that complicated things should be investigated in their complexity. Instead of using the classical reductionist - insulation approach, where it was attempted to interpret occurring phenomena in a category of simple cause and effect chain, he proposed the systems approach in which there are a multi-way and multi-direction interaction as well as cyclic character of influences. According to P. Senge in the systems approach the ability of systems thinking is the most important, which should begin with questioning the previous way of organization perception and phenomena occurring in it. He postulates a change of way of thinking and looking at organization. Instead of seeing linear cause and effect chains, he suggest seeing multi-direction, mutual relations. Instead of static snapshots, he proposes seeing the processes of changes [14]. In the systems thinking it is necessary to recognize the structure in which we function in order to let ourselves free from interactions not seen before and use the interactions which are beneficial for us. Typical structure patterns are repeated and systems archetypes should be used for their recognition. They provide a picture of mutual relations taking place in systems, therefore they may be used for the construction of reliable hypotheses concerning powers driving the systems. The possibilities of applying systems archetypes in different situation were confirmed by, among others, E. Wolstenholm [17, 18]. The use of systems thinking was also proved in the conception of learning organization [14, 16], knowledge management $[2,4,10,11]$ or in change management [12]. The author of the work, as the first one, decided to use the systems approach for analysis of unfavorable phenomena occurring in the quality management system.

The purpose of the work is to present own methodology of problem analysis in the quality management system, based on systems thinking.

\section{EXAMINING THE PROBLEMS IN THE QUALITY MANAGE- MENT SYSTEM}

The author the work has been conducting research for many years on the certified quality management systems consistent with the ISO 9000 series of standards [5, 9]. One of the research directions is to investigate problems 
occurring in the system [8]. The author intended to identify problems in the certified quality management system and link them with the profile and size of organization, thus he used qualitative research. He elaborated his own method of problems examination which consists in the analysis of results of audits conducted by the third party. The assumptions and description of research method are presented in [7]. Quantitative research provided a great number of information, nevertheless they do not provide possibilities for discovering and describing the phenomena occurring in the quality management system. In order to answer the question what problems appear on the particular stages of creation, maintenance and development of the quality management system and what their causes are, the qualitative research was conducted. It was decided to apply a collective case study carried out on a sample of 30 organizations. The research results were presented in [6]. Various information was obtained concerning the problems appearing on the particular stages of system creation and functioning as well as their causes. However, if one wants to describe the action mechanism and explain the reasons for unfavorable phenomena appearing in the system it is necessary to apply a new approach. The author decided to adopt the rules of systems thinking. It is a pioneer use of systems thinking for describing the phenomena occurring in the quality management system. When adopting the rules of systems thinking, the perception will be directed on the system's entirety, on its mutual relations and its changes in time. Systems archetypes will be used for description of action mechanisms of unfavorable phenomena.

\section{OWN METHODOLOGY OF PROBLEM ANALYSIS IN THE SYSTEM}

In order to determine the mechanisms of phenomena taking place in the system and discover their causes, the information obtained in the qualitative research was used and the rules of systems thinking were applied. Own methodology elaborated of problem analysis in the quality management system may be described in the following steps:

1. Determining problems occurring on particular stages of system creation and functioning.

2. Precise description of situation taking place in a particular case.

3. Presentation of situation which we want to investigate in a perspective of systems thinking.

4. Selection of appropriate systems archetype which will be the best for describing a particular situation.

5. After a final selection of systems archetype, description of phenomena occurring in a particular situation and their fulfillment by other vital elements.

6. Analysis of situation with considering what influences on variable data.

7. Raising a multiple question "why?" in order to determine all reasons affecting the analyzed phenomena.

8. Confirming the pattern of behavior resulting from the adopted systems archetype and comparing whether they correspond with the patterns that we perceive in the story described.

In the first step it is necessary to identify all the problems which may appear on the stage of creation, maintenance and development of the quality management system. Basing on qualitative research results, it is possible to indicate problems appearing on different stages of system creation and functioning. Nevertheless, one should be aware that these are potential problems which may take place in each organization. But whether there is one or bigger number of problems generated in a particular organization, it depends on its situation and other factors. Thus, the assumption was accepted that it is better to describe the potential threats that lead to problems creation. Another difficulty is systematizing threats in time and assigning them to the particular stages of system creation and development. There may be a threat indicated which appear on a particular stage one time only. However, there are also threats which may appear a multiple number of times and on different stages. Despite the difficulties, it is necessary to elaborate a systematized list of threats in relation with the stages of system creation and functioning as well as with the passing time. The second step is to describe a situation precisely occurring in a particular case. The description of particular threat constitutes a basis for further analysis and therefore, it should be conducted reliably. In the third step we aim at presenting the situations in a perspective of systems thinking. We try to look at a threat in a context of multi-direction and mutual relations and see the process of changes occurring in time. The fourth step is the selection of appropriate systems archetype which will fit the situation described best. The selection of appropriate systems archetype lies within expert's competence who investigated situations and has appropriate knowledge regarding archetypes. From the group of several common archetypes there should be one chosen which is the best for describing a particular situation. When selecting an appropriate archetype, the elaborated listings of behavior patterns and corresponding archetypes may be of help, also one may use a family tree of archetypes. In the fifth step, having the appropriate systems archetype chosen, there should be phenomena described that take place in a particular situation, see causality and interaction loops of individual elements with others. When describing the situation in a system perspective it is necessary to fulfill it with vital elements that enable a total description of phenomena. In the sixth step there should be situation analysis conducted, answer the question what phenomena take place in a particular case, what influences on individual variables. In this step there should be mechanism of unfavorable phenomena described as well as the factors affecting it. In the seventh step there are all causes investigated which have influence on the analyzed phenomena. Raising a multiple question "why" and observation of occurring phenomena in a perspective of systems thinking should provide sufficient information. The final, eighth step is confirmation if the described behavior pattern resulting from the adopted systems archetype adequate for the situation we 
examine. It is an ultimate confirmation whether the described behavior pattern corresponds with the real behavior patterns in the analyzed case.

\section{VALIDATION OF THE METHODOLOGY OF ANALYZING PROBLEMS IN THE SYSTEM}

In order to test the designed methodology of analysis of problems in the quality management system in practice, described in eight steps, the author, based on the results of the qualitative research conducted, identified 11 threats that were arranged grounding on the criterion of time. For each threat the author, using his own methodology, determined the action mechanism of unfavorable phenomena as well as their causes. For the purpose of this problem, 2 threats were chosen. A brief presentation of the third and tenth threat is treated as an example of validation of the designed methodology.

The third threat for the system is lack of coherence between quality management system and management, strategy and business. Quality management system is a typically management system which must be adequately fitted into existing configuration of organization's management. The mechanism of this threat may be depicted by the archetype "destructive cures" (Fig. 1).

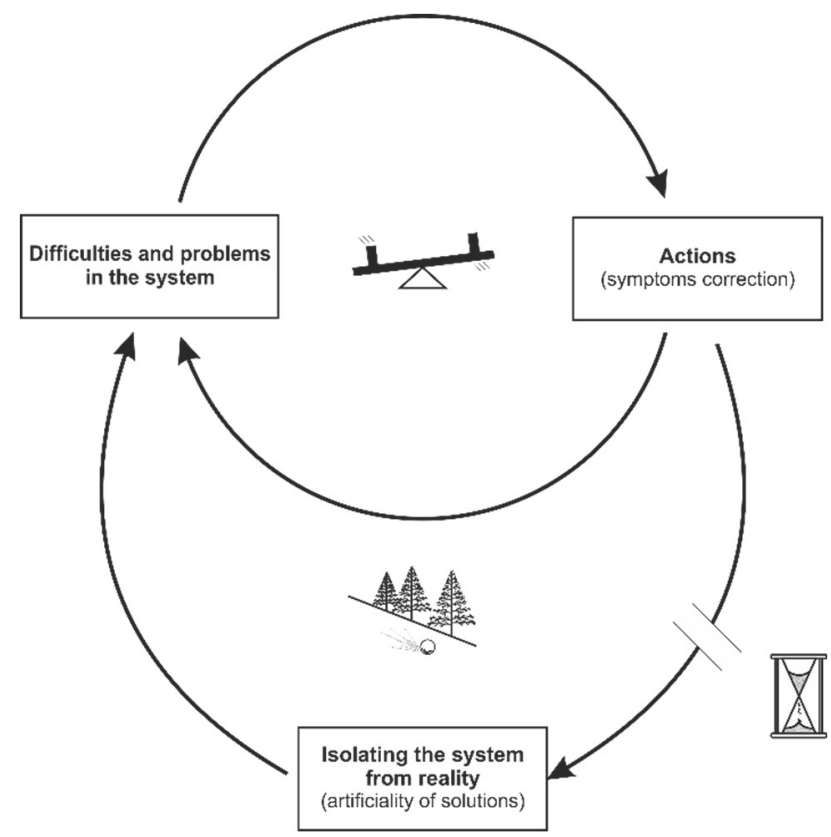

Fig. 1 Threat mechanism connected with the lack of coherence between the system and management, strategy and business Source: own work based on the archetype pattern - destructive cures [16].

Lack of coherence between the system and management, strategy and business will cause difficulties linked to the system functioning and problems appearance. The people operating the system will notice its worse functioning. Not knowing the real causes of difficulties arising from the lack of coherence between the system and management, strategy and business, they may undertake actions correcting the symptoms of difficulties. Such actions may weaken unfavorable symptoms in a short term or even cause a short-term improvement. Such system's behavior will convince the people operating the system that their actions are adequate. When the problems and difficulties appear again, the people operating the system will take similar actions in order to correct the problems. The effects of such actions will certainly be lower than the previous ones, what may induce them to amplify the actions of such type. If the system's behavior shows even a shortterm stabilization, the people operating the system will think that their actions bring benefits but they only need to be intensified. Implementing more intensive actions directed on mitigating the symptoms of the disease without searching for its reasons will cause that the disease is going to develop although some of its symptoms may be weakened. In reality, the problems and difficulties will deteriorate in the system. Even bigger system's isolation from the reality is going to appear. Despite the deep efforts of people who try to mitigate the symptoms of problems, the system with the passage of time will work even worse and will be even more artificial. Analyzing the reasons of the hereby threat, the complexity of such situation should be noted. A direct reason of the threat is poor knowledge and awareness of the top management who does not feel the need for linking the quality management system with management, strategy and business. Getting deeper, it turns out that the theory and especially practice is not sufficient in this area.

The tenth threat is inappropriate system maintenance. In order to enable a proper system functioning, the involvement of the top management and employees is needed as well as the adequate decisions and actions, in addition with proper monitoring and assessment. The system deprived of management's support, inappropriately serviced and assessed will work even worse and will cause limitation of the functions that it realizes. Inability to collect, process and use the information generated by the system will result in the lack of necessary information for decision-making. Lack of or inadequate decisions will effect in deterioration of system functioning. In order to prevent such difficulties, actions should be taken. If taking radical and serious repair actions requires a lot of time and involvement, the organizations starts to test quick but superficial solutions which at least partially limit the symptoms of problems. The organization is getting more persuaded to quick actions that require little effort. Such actions will bring benefits in a short perspective of time, which will be even more convincing of their appropriateness. The real difficulties and problems will obviously grow but they will not be visible very well then. This leads to addiction to superficial actions. The mechanism of this threat may be described by the "burden transfer" archetype (Fig. 2).

The organization, neglecting an appropriate system maintenance and evaluation, is going to meet new problems which are going to cause its increasingly worse functioning. Such disturbances are interpreted and the organization is forced to take repair actions. Radical changes require a lot of time, involvement and effort but the organization is already delayed in taking actions. Thus, it takes quick, superficial and ostensible actions, of which effects 
will be quickly visible. Actions of such type bring one result, they lead to weakening at least some symptoms of the problems.

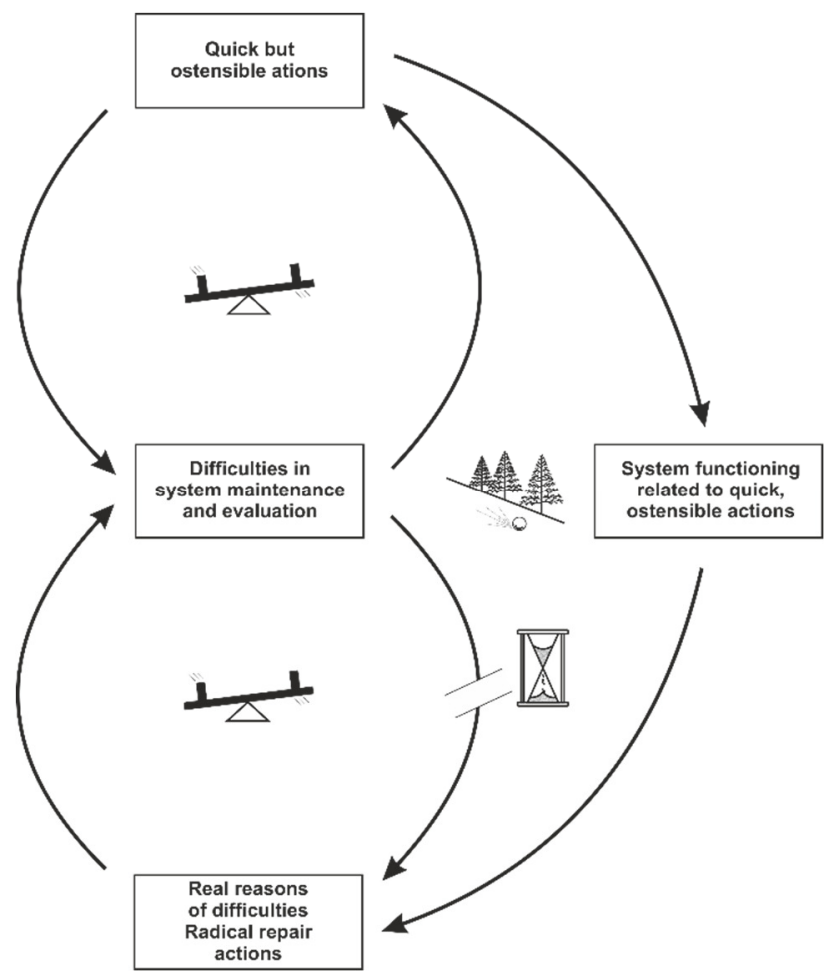

Fig. 2 Threat mechanism connected with inappropriate maintaining of the system

Source: own work based on the archetype pattern - burden transfer [16]

The organization perceives it as a success of actions of such type and starts to engage in them more. Of course, difficulties and problems have not been resolved, the system functions worse, there have been only symptoms of unfavorable phenomena mitigated. The organization gradually addicts to ostensible and superficial but quick, not requiring a lot of involvement, actions. Gradually, the ability to recognize real reasons of problems and difficulties decreases in the organization as well as the ability to take adequate actions. Further, even ostensible success, connected with limitation of unfavorable phenomena is only going to convince the organization that its actions are correct. The addiction to superficial and ostensible actions increases and the organization concentrates on such type of actions. Real difficulties and problems are going to increase all the time and it increases the need of quick reaction to such type of phenomena even more. The system is functioning even worse, it is becoming more superficial and ostensible, and the organization trusts more and more in quick and superficial actions. An additional consequence of this type of actions is continuing discouragement of people to work in the system and their negative attitude towards it. When searching for the causes of this threat, there may be the following taken into account: awareness, knowledge and time. Low awareness of the management allows to adjust quick but superficial actions. However, the limited knowledge causes that the organization does not see the negative consequences and gradual addiction to such type of actions.

\section{CONCLUSION}

The author set as his goal to design a new methodology of problem analysis in the quality management system using systems thinking. It is the first attempt of using systems thinking for describing unfavorable phenomena taking place in the system. The author conducted a collective case study, which provided the necessary information to analyze problems. Problems appear on various stages of system creation and functioning. These particular problems have impact on other problems in a lesser or greater degree, usually enhancing their harmful influence on the system. Each problem in the system leads to other unfavorable phenomena that become stronger with time. Different rate of spreading of unfavorable phenomena was confirmed, but in each case with the passing time these phenomena become stronger and their harmful impact on the organization increases. Each unfavorable phenomenon has its own cause or a group of causes, sometimes distant in time and space. It enables identification of all potential threats that may appear in the system on different stages of its creation and functioning as well as prioritizing those threats in time. The elaborated methodology based on eight steps allows to describe the mechanism of unfavorable phenomena and explain their causes. Each threat may have an appropriate systems archetype assigned, which will make it possible to describe and analyze phenomena occurring in a given situation. The use of rules of systems thinking should also lead to explaining of all causes of unfavorable phenomena. The designed methodology of problem analysis was subjected to the process of validation based on the example of eleven threats, two of which have been presented in this work. It confirms the practical possibilities of using the designed methodology. The new approach allows to perceive multi-directional relations and processes of changes occurring in time. Proper identification of the structure could provide information about the impacts that have not been noticed before and thereby it would make it easier to free oneself from those impacts. In the designed methodology attention is paid to the meaning of dynamics of the phenomena occurring in the system. There is a need to look for new methods and research tools, so it is possible to interpret the dynamics better of the phenomena in the system and their influence on organizations.

\section{REFERENCES}

[1] M. Jackson. Systems methodology for the management sciences. Plenum Press, New York, 1990.

[2] M.C. Jackson. Systems thinking: Holism for managers. Wiley, Chichester, 2003.

[3] R. Floor and M. Jackson. Creative problem solving: Total systems intervention. Wiley, Chichester, 1991.

[4] J.P. Kawalek. "Systems thinking and knowledge management: positional assertions and preliminary observations", Systems Research and Behavioral Science, no 21, 2004, pp. 17-36.

[5] M.J. Ligarski. „Ocena systemu zarządzania jakością wyniki badań”, Towaroznawcze Problemy Jakości, nr 4 (13), 2007, pp. 25-35. 
[6] M.J. Ligarski. Podejście systemowe do zarzqdzania jakościq w organizacji. Monografia, Wyd. Politechniki Śląskiej, Gliwice, 2010.

[7] M.J. Ligarski. "Problem identification method in certified quality management systems", Quality \& Quantity, vol. 46, 2012, pp. 315-321.

[8] M.J. Ligarski. "Problems examination in quality management system", Acta technologica agriculturae vol. 16, no. 4, 2013, pp. 106-110.

[9] M.J. Ligarski. „Diagnoza systemu zarządzania w polskich organizacjach", Problemy Jakości, nr 5, 2014, pp. 14-22.

[10] Paucar-Caceres. "Operational research, systems thinking and the development of management sciences methodologies in the US and the UK", Scientific Inquiry: A Journal of the International Institute for General System Studies, vol. 9, no. 1, 2008, pp. 318.

[11] Paucar-Caceres and R. Pagano. "System thinking and the use of systemic methodologies in knowledge management", Systems Research and Behavioral Science, no. 26, 2009, pp. 343-355.

[12] L.L.R. Rodrigues, N. Dharmaraj, B.R. Shrinivasa Rao. "System dynamics approach for change management in new product development", Management Research News, vol. 29, no. 8, 2006, pp. 512-523.

[13] P.M. Senge. The fifth discipline The art and practice of the learning organization. Doubleday/Currency, New York, 1990.

[14] P.M. Senge. Piq̨a dyscyplina Teoria i praktyka organizacji uczqcych się. Oficyna Ekonomiczna, Polskie Wydawnictwa Profesjonalne sp. z o.o., Wolters Kluwer Polska sp. z o.o., Warszawa, 2006.

[15] P.M. Senge, A. Kleiner, C. Roberts, R.B. Ross, B.J. Smith. The fifth discipline Fieldbook Strategies and tools for building a learning organization. Doubleday, London 1994.

[16] P.M. Senge, A. Kleiner, C. Roberts, R.B. Ross, B.J. Smith. Piqta dyscyplina materiały dla praktyka Jak budować organizację uczqca się. Oficyna Ekonomiczna, Polskie Wydawnictwa Profesjonalne sp. z o.o., Kraków, 2002.

[17] E. Wolstenholme. "Towards the definition and use of a core set of archetypal structures in system dynamic", System Dynamics Review, vol. 19, no. 1, 2003, pp. 7-26.

[18] E. Wolstenholme. "Using generic system archetypes to support thinking and modeling", System Dynamics Review, vol. 20, no. 4, 2004, pp. 341-356.

dr hab. inż. Mariusz J. Ligarski, prof. PŚ.

Silesian University of Technology

Faculty of Organization and Management

Institute of Production Engineering

Roosevelta 26, 41-800 Zabrze, Poland

e-mail: Mariusz.Ligarski@polsı.pl 